for patients with families. An advocate for one person is morally debarred from making decisions when more than one have legitimate interests at stake.

We must, then, move beyond the ethics of the dyad or even the contemporary triad. Instead, we must learn to think in terms of family justice. Fairness to all concerned will be a major factor in determining both who should decide and also what is the appropriate treatment at the end of life. That's the way decisions by and for people with families ought to be made-with everyone thinking about what will be best and fairest for all.

This idea might seem hopeless because families are so different and have such different conceptions of justice. We certainly have no theory of familial justice that is even remotely adequate. But questions of family justice cannot be legitimately avoided. Attempts to do so marginalize people. If families emerge from their invisibility, we will all be able to see many cases in which benefits to patients are not sufficient to justify the burdens they impose on their families. Ask yourself, Would you rather lose your career and all your savings at age fifty-five, or lose a $\mathbf{5 0}$ percent chance of living an extra year with a terminal disease at age eighty-three? Would anyone prefer the chance of an extra year?

But a health care system sensitive to the burdens treatment decisions impose on families is nowhere in sight. In fact, those who focus on the doctor-patient dyad will not even agree that such a system would be morally legitimate. In the foreseeable future, then, families will continue to be invisible, marginalized, or reduced to means. Costs will, no doubt, continue to be shifted to families. We will continue to be largely oblivious to the impact of our health care system and our treatment decisions on their lives.

In this context, the better the fam; ily-the more loyal, sensitive, and loving the caregivers within the family-the more we will take advantage of their resources and virtues. Un- able or unwilling to divorce herself from her terrified and dying mother, Jane just keeps trying to hang in there. She and I have developed a little ritual. "How ya doing?" I ask when our paths cross. "I'm still vertical," Jane responds. "That's terrific, Jane, just terrific!" We smile sadly at the gallows humor. But the last time I saw her, she said, "If this goes on much longer, Mom is going to outlive me."

\section{References}

1. Kenneth E. Covinsky et al., "The Impact of Serious Illness on Patients' Families," JAMA 272 (1994): 1839-44.

2. Many patients agree. There is beginning to be evidence that patients would prefer that life-prolonging treatment be discontinued when it has a serious financial impact on their family members. (See, for example, Ashwini Sehgal et al., "How Strictly Do Dialysis Patients Want Their Advance Directives Followed?" JAMA 267 (1992): 59-63.) But the interests of other family members do not have standing because the patient wants them considered; they have standing whether or not the patient wants to consider them.

\title{
From Consumer Choice to Consumer Welfare
}

\author{
by Carl E. Schneider
}

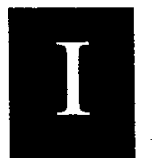

n trying to understand the SUPPORT study, it may be useful to think of contemporary bioethics reform in terms of the principles of consumer protection. The central tendency of

Carl E. Schneider is a professor at the University of Michigan Law School, Ann Arbor.

Carl E. Schneider, "From Consumer Choice to Consumer Welfare," Special Supplement, Hastings Center Repont 25, no. 6 (1995): S25S27. that reform (particularly in my own field-the law) has been to employ the model of consumer choice. That model sets as its purpose to allow consumers to choose the kinds of products they prefer. It seeks to accomplish that purpose primarily by supplying consumers the information they need to make choices and by insisting that they are given what they chose. Thus, for example, merchants may be required to reveal the actual terms under which they sell goods on credit, so that customers may decide whether they wish to pay the price. And once the customer has chosen a purchase, the merchant is held to the terms originally agreed upon. In short, the consumer choice model seeks to allow customers to make successful choices by providing them with a market that works in the economist's sense, efficiently.

Bioethical reform may be understood along these lines. The doctrine of informed consent is, plainly, intended to provide patients the information they need to make wise choices that express their preferences. The patient is thus to become a consumer well-enough informed to make sensible choices in the market for medical care. The patient's choices are then given more binding effect by, for example, various provisions for advance directives.

The consumer choice model is hardly startling and surely makes a good deal of sense. The free-market prescription was, for instance, quite 
successful when it was employed during the New Deal to improve the operation of the securities market. But of course the consumer choice model rests on some consequential assumptions. It assumes, for one thing, that human preferences differ so much that it is best to let people make purchasing decisions for themselves. It assumes an engaged and energetic purchaser. Finally, it assumes that people's preferences are clear and strong enough to drive them to act on the information they receive to make choices and follow up on them. Thus the New Deal reforms of the securities markets were plausible because many of the people who trade in that market know their way around it, have ready access to the information that is provided, have commanding incentives to use it, and know how to do so.

The SUPPORT study does not speak directly to all these assumptions. Nor could any single study definitively establish whether such assumptions are true. Nevertheless, this ambitious and impressive research raises some fruitful questions about the consumer choice model as it has been applied in medicine. The SUPPORT enterprise followed that model in trying to increase the communication between doctor and patient so that both could make better decisions. But what is striking about the study is, despite a commitment of resources (and, one suspects, enthusiasm) unlikely to be even matched, much less sustained, in the dullness of daily life, the SUPPORT instantiation of the model quite failed to produce statistically significant benefits.

What are we to make of this unsettling negative? To put the point simply, a strong reading of the study raises questions about the usefulness of continuing to emphasize the consumer choice model. In saying this, I am far from suggesting that efforts to implement the consumer choice model in bioethics have been wasted. I suspect that that model has helped spur changes in medical attitudes which were necessary to make doctors' behavior more tolerable to contemporary American mores. My point, rather, is that-strongly read-the SUPPORT study provokes doubts about the profit of sustaining the consumer choice model at its present preeminence.

But how strongly should we read the SUPPORT data? Our answer will depend on many things. But one reason to read it strongly is that SUPPORT seems to confirm what we already know about the effects of some other bioethical reforms in the consumer choice model-that those reforms often seem to have fewer consequences than the consumer choice model seems to call for. Arthur Caplan, for instance, reports, "No more than 10 percent of the population has either a living will or a durable power of attorney." He adds, "Similarly dismal statistics are reported for the practices surrounding the issuance of DNR (do-not-resuscitate), DNI (do-not-intubate), and DNT (do-not-treat) orders in hospitals and nursing homes." Likewise, studies of informed consent suggest the clumsiness with which doctors communicate with patients, the awkwardness with which patients assimilate what they are told, and the uncertain consequences of what patients learn. Jay Katz thus concludes glumly that the law "has had little impact on patients' decisionmaking either in legal theory or medical practice." Some substantiation of this conclusion lies, for example, in the fact that "the empirical and anecdotal studies of patients who refuse treatment almost never portray the process of obtaining informed consent as playing a causative role."

In short, the SUPPORT study is not alone in raising real questions about the extent to which the consumer choice model actually improves the lives of medical patients. Nor is it surprising that patients do not take full advantage of reform's proffers of information and the means of effectuating their decisions. After all, consumers of all kinds seem to behave in this way. Consumers for years told pollsters that they wanted cars with seat belts, airbags, and other safety devices, that they wanted fuel-efficient cars, and so on. Yet they did not seem to use their buying power to compel the market to provide them with those commodities.

Part of the reason for this kind of disappointment is that sellers do not always respond rationally to the market's incentives. But other reasons lie in the consumer choice model's assumptions I described earlier. Consumers' preferences are often undeveloped, weak, and conflicting. Furthermore, as an economist would say, making and implementing decisions often imposes high transaction costs. And as a social psychologist might point out, reaching decisions is painful, and many people dislike and resist it. Thus it is to be expected that studies of consumers often show that they do not seem to make effective use of the information the law has labored to supply to them.

All this is no less true of making medical choices than buying cars. We tend to believe that because medical decisions are so consequential in patients' lives, patients must have strong opinions about them that they wish to put into action. In fact, however, there is considerable empirical evidence that some substantial proportion of patients do not yearn to make their own medical decisions. ${ }^{4}$ No doubt part of the reason for this is the one the authors of the SUPPORT study propose-that patients, strangers in a strange land, are trying to accommodate themselves to local custom. But I think that the reasons run a good deal deeper than this, into people's sense of their own competence, into the vigor with which sick people can exert themselves, even into questions about where people's sharpest concerns and most active interests lie. ${ }^{5}$

In short, the SUPPORT study and other studies like it raise the possibility that in the medical context the consumer choice model may at some point confront strong resistance not just from the structure of medicine and the imperialism of doctors, but in the hearts and minds of patients. One legitimate response to such a suggestion is to say that we must fight it out along these lines however long it takes, because the principle of patient autonomy is too cherished to compromise. But if my speculations about the SUPPORT study are correct, such a battle is hardly an appetizing prospect.

What, then, is to be done? Our analogy to consumer protection sug- 
gests one kind of answer. The consumer choice model has long been supplemented with what we may loosely call the consumer welfare model. When the market failed to deliver fuel-efficient cars equipped with airbags quickly enough, we created regulatory incentives for them. Similarly, it may now be time for bioethics to accelerate a shift that seems already to have begun-away from patient choice and toward changing the medical care system so that it delivers a better product. To put the point provocatively, it may be time to think about giving patients what we think they want, but have not been able to secure for themselves. We might even consider trying to give patients what we think they would want if they thought about it

Or, to make the suggestion less wickedly, perhaps we should redirect our attention away from the procedures by which medical decisions are made and toward the substance of those decisions. Bioethics has historically looked to the former, in part (albeit only in part) because it was supposed to lead to the latter. Common sense has been supposed to suggest that if patients were supplied with good information, they would make wise, or at least satisfying, decisions. But the SUPPORT study helps to suggest doubts about whether the procedural approach improves decisions or even patients' satisfaction with decisions. If these doubts are well-founded, one response is to look directly at those decisions and to try to improve them.

But truth, what is that? said jesting Pilate. How may we know a good choice when we see it? Are not people's preferences so varied that we cannot usefully prescribe for them? There is obviously much to be said for this objection. But there are also several things to be said against it. Let me suggest three.

First, I am not proposing that we coerce or deceive patients into what we think is good for them. Rather, I suggest that we try to develop some degree of social consensus-where it is possible to do so- on questions of bioethical relevance and difficulty. In other words, we may find it helpful to furnish patients with well-thought- out answers to standard kinds of bioethical problems. Patients would, crucially, be able to reject those answers, but the answers would be there for patients to consult, and they would be the default solution and their doctors, and as they see new problems with new eyes. Further, the preferences they develop (whether before or after they become ill) will arise from and be shaped by prevailing cultural atti-

It may now be time for bioethics to accelerate a shift that seems already to have begun-away from patient choice and toward changing the medical care system so that it delivers a better product.

where patients would not or could not act.

Of course, there are effectively default positions now, as the SUPPORT study implies. But these positions today may insufficiently represent the views and interests of patients and overrepresent those of doctors. Where the consumer choice model cannot solve those problems of representation, the consumer welfare model may at least be able to create a kind of countervailing force.

The second response to the view that patients' preferences vary too much to make consensus possible is that it is probably not true about every issue. The SUPPORT study, for instance, notes that a troubling number of dying patients suffer a disquieting amount of pain. And it is now widely observed that physicians have not always taken the fullest advantage of progress in pain management. It might be more profitable to look directly to ways of getting doctors to treat pain more aggressively than to try to do so indirectly by increasing patient choice.

Third, it is important to realize that quite often people do not have preferences about their medical care before they become ill, and that what preferences they may have are sometimes inchoate, ill formed, and insubstantial. Instead of existing before illness, patients' preferences often develop as patients come to see what it is like to be sick, as they interact with their family, their friends, tudes. The kind of effort I am proposing for bioethics may help shape the cultural attitudes that shape patient attitudes, so that the default position that develops out of it will seem agreeable to many patients.

Indeed, we are already seeing progress toward establishing the kind of default position the consumer welfare model calls for in just one of the areas the SUPPORT study treatsend-of-life decisions. Through processes like the social discussion of cases from Quinlan and Cruzan we seem to be moving toward a cultural consensus that patients in persistent vegetative states should not be kept alive when hope is gone. And under the mantra "quality more than quantity," we-the public, patients, and doctors-are in my observation moving, even if less swiftly, toward a greater reluctance to treat dying patients in the excessive way the SUPPORT study implicitly criticizes.

The SUPPORT study suggests yet another reason it may be more profitable to look directly at what medicine does rather than at how to increase patients' autonomy. SUPPORT was conducted in notably bureaucratic settings. That is where a telling number of critical medical decisions are now made. And that is where they will increasingly be made. Our experience with bureaucracies suggests that giving clients an authoritative voice in them can be implacably difficult: so often the cure for the ills of bureaucracy is more bureauc- 
racy. For example, clients' decisional claims are commonly protected through due process sorts of solutions. But the research on due process protections finds that they regularly disappoint. Bureaucrats often see due process devices as irrational impositions, and respond to them formalistically. Clients overwhelmingly fail to use such due process favorites as the right to a hearing. ${ }^{6}$ What is more, due process remedies lengthen the process of decision without necessarily yielding happier results. This suggests to me that it will often be better to deliver the "right" service in the first place.

It is surely desirable to structure medical care in such a way that patients are as involved in it as they want to be. That is what the consumer choice model does and is right to do. But we need to ask where to put reformist energy, and that model may, for the time at least, have done much of what it can for us. It may thus be time to strengthen efforts toward a consumer welfare model. Building default positions that are more satisfactory than some of the ones we now have, and that acknowledge that not everything can be accomplished by giving patients autonomy, is one way to start. But the SUPPORT study suggests one more cautionary note. It is harder to change human behavior and social institutions than we like to think. And in this regard, enterprises of great pitch and moment their currents turn awry and lose the name of action.

\section{References}

1. Arthur L. Caplan, "Can Autonomy Be Saved?" in If I Were a Rich Man Could I
Buy a Pancreas?And Other Essays on the Ethics of Health Care (Bloomington: Indiana University Press, 1992), pp. 256, 261.

2. Jay Katz, "Informed Consent: A Fairy Tale," University of Pittsburgh Law Review 39 (1977): 137, 139.

3. Paul S. Appelbaum, Charles W. Lidz, and Alan Meisel, Informed Consent: Legal Theory and Clinical Practice (New York: Oxford University Press, 1987), p. 202.

4. For a survey of these data, see Carl E. Schneider, "Bioethics with a Human Face," Indiana Law Journal 69 (1994): 1075.

5. I explore this difficult topic at great length in Carl E. Schneider, "Patients, Doctors, and Decisions: Re-Examining Autonomy" (in manuscript).

6. See, for example, Carl E. Schneider, "Lawyers and Children: Wisdom and Legitimacy in Family Policy," Michigan Law Review 84 (1986): 919.

curtail unnecessary, often expensive procedures and tests, and in part from the recognition that traditional continuing medical education has had very little impact on physicians' clinical practice. ${ }^{1}$

Whether directed to physicians or others, there is a standard method for designing interventions that includes the selection of an appropriate target audience, program goals, and messages as well as methods for delivery, implementation, and evaluation. Well-designed interventions are informed by empirical research on the current beliefs, attitudes, and practices of the target audience and on the barriers and incentives that are likely to impede or encourage adoption of the new behavior. Ideally, there is an articulated theory of behavior change driving decisions about the content and structure of the intervention and an explicit understanding on the part of the design team about the values upon which the intervention is premised. In short, sound behavior change interventions are theory driven, explicit about value assumptions, and empirically based.

Although the SUPPORT study does not address the theory of change that guided the design of its inter- 